DOI: $10.15593 / 2499-9873 / 2020.4 .09$

УДК 51-74

\title{
Л.В. Кожемякин
}

Пермский национальный исследовательский политехнический университет, Пермь, Россия

\section{ПРИМЕНЕНИЕ НЕЙРОННЫХ СЕТЕЙ \\ В МОДЕЛИРОВАНИИ КЛАСТЕРНО-СЕТЕВЫХ СВЯЗЕЙ В НЕФТЕГАЗОВОЙ ОТРАСЛИ}

\begin{abstract}
Несмотря на то, что кластерный подход достаточно распространен в научных работах, вопросы формирования, развития и оценки эффективности кластерно-сетевых взаимодействий остаются нерешенными. Исследования научного сообщества базируются преимущественно на качественных методах кластерного анализа (экспертный анализ, ретроспективный анализ, метод сопоставлений аналогов и т.д.), однако необходимость трансформации регионального развития и переход к неоэкономике требуют применения экономико-математических методов анализа, а их арсенал относительно невелик, что с необходимостью вызывает поиск новых решений. Предпринята попытка моделирования кластерно-сетевого механизма в нефтегазовой отрасли с применением нейронных сетей, так как нефтяная сфера - один из ключевых секторов российской экономики, который влияет на определяющие темпы и пути социально-экономического развития государства, подвержен наибольшему регулированию со стороны правительства страны, чем большинство других отраслей. Самой важной специфичной чертой нефтяной сферы выступает то, что она не только способна генерировать огромные денежные ресурсы, но и аккумулировать их для решения большого числа социально-экономических проблем. По результатам обученной нейронной сети на примере показателей Пермского края были сделаны прогнозные значения валового регионального продукта и как возможное ядро кластера нефтяной отрасли - прогноз прибыли компании группы ЛУКОЙЛ.

Ключевые слова: нейронные сети, нейросетевое моделирование, добыча полезных ископаемых, нефтегазовая отрасль, управление в нефтегазовой отрасли, вертикально-интегрированные нефтяные компании, кластерно-сетевые связи, индекс кластерной нагрузки, региональное развитие, валовой региональный продукт.
\end{abstract}

\section{L.V. Kozhemyakin}

Perm National Research Polytechnic University, Perm, Russian Federation

\section{APPLICATION OF NEURAL NETWORKS IN SIMULATION OF CLUSTER-NETWORK RELATIONS IN OIL AND GAS INDUSTRY}

Despite the fact that the cluster approach is quite common in scientific works, the issues of the formation, development and evaluation of the effectiveness of cluster-network interactions remain unresolved. The research of the scientific community is based mainly on qualitative methods of cluster analysis (expert analysis, retrospective analysis, comparison method, etc.), however, the need to transform regional development and the transition to neo-economics require the use of economic and mathematical methods of analysis, and their arsenal is relatively small. which necessitates the search for new solutions. An attempt is made in the 
work to simulate the cluster-network mechanism in the oil and gas industry using neural networks, since the oil sector is one of the key sectors of the Russian economy, which influences the determining rates and paths of the country's socio-economic development, and is subject to the greatest regulation by the government of the country than most other sectors. The most important specific feature of the oil sector is that it is not only able to generate huge monetary resources, but also to accumulate them to solve a large number of socioeconomic problems. Based on the results of the trained neural network, using the example of the indicators of the Perm Territory, predicted values of the gross regional product were made and, as a possible core of the oil industry cluster, the profit forecast of the company of the LUKOIL group.

Keywords: neural networks, neural network modeling, mining, oil and gas industry, management in the oil and gas industry, vertically integrated oil companies, cluster network relations, cluster load index, regional development, gross regional product.

Вопросы кластерно-сетевого развития в настоящее время требуют значительного внимания, и, несмотря на исследования в этой области как отечественных, так и зарубежных специалистов, до сих пор нет единого подхода к решению проблем регионального развития, что особенно актуально в условиях отказа от института отраслевого управления экономического развития. Обоснование управленческих решений по социальноэкономическому развитию систем требует переосмысления научных взглядов на кластерно-сетевые процессы и взаимодействия [1].

В работе предпринята попытка моделирования кластерносетевых связей в нефтегазовой отрасли на примере регионов Приволжского федерального округа с помощью применения метода нейросетевого моделирования.

Приволжский федеральный округ занимает вторую позицию по добыче нефти, тем самым вносит значительный вклад в одну из превалирующих отраслей российской экономики: предприятия нефтегазового комплекса дают более четверти объема производства промышленной продукции России, тем самым формируя весомые налоговые поступления и прочие доходы в бюджет страны. Нефтегазовый комплекс относится к промышленному производству и является обобщенным названием группы отраслей, в которую входят отрасли по добыче, транспортировке и переработке нефти [2].

Кроме нефтедобычи, Приволжский федеральный округ характеризуется типом деятельности, обозначенным Росстатом как «обрабатывающие производства», включающим в себя множество подотраслей. Однако мы считаем, исходя из первичного анализа статистических данных по регионам России, что Приволжский федеральный округ имеет смешанный тип деятельности, т.е., кроме экономической деятельности «обрабатывающие производства», характерным типом деятельности является «добыча полезных ископаемых». Для построения кластерно-сетевых связей 
и анализа зависимости регионального развития от индекса кластерной нагрузки предлагается рассматривать промышленную кластеризацию применительно не ко всей региональной экономике, а применительно к ведущей отрасли. Для детального анализа воспользуемся авторской методикой типологизации регионов для выделения двух групп, каждая со своей доминирующей отраслью. Подробная методика нахождения показателя $k_{i}$ рассмотрена в предылущуем исследовании, основные выкладки представлены в опубликованной статье [3].

Экономический кризис, начавшийся в 2008 г., в той или иной степени повлиял на все регионы Российской Федерации. Исходя из рис. 1, 2, можно говорить о росте валового регионального продукта в рассматриваемых регионах. Но довольно часто оценка социальноэкономических процессов выполняется некорректно с использованием абсолютных показателей, так как трудно адекватно проследить тенденции развития исследуемого процесса и выполнить прогноз его дальнейшей эволюции [4]. Ввиду этого перейдем от абсолютных показателей к относительным, позволяющим выполнить сравнительный анализ несопоставимых в абсолютных единицах процессов, что, в свою очередь, открывает возможности для сравнения уровней развития или распространенности различных общественных явлений.

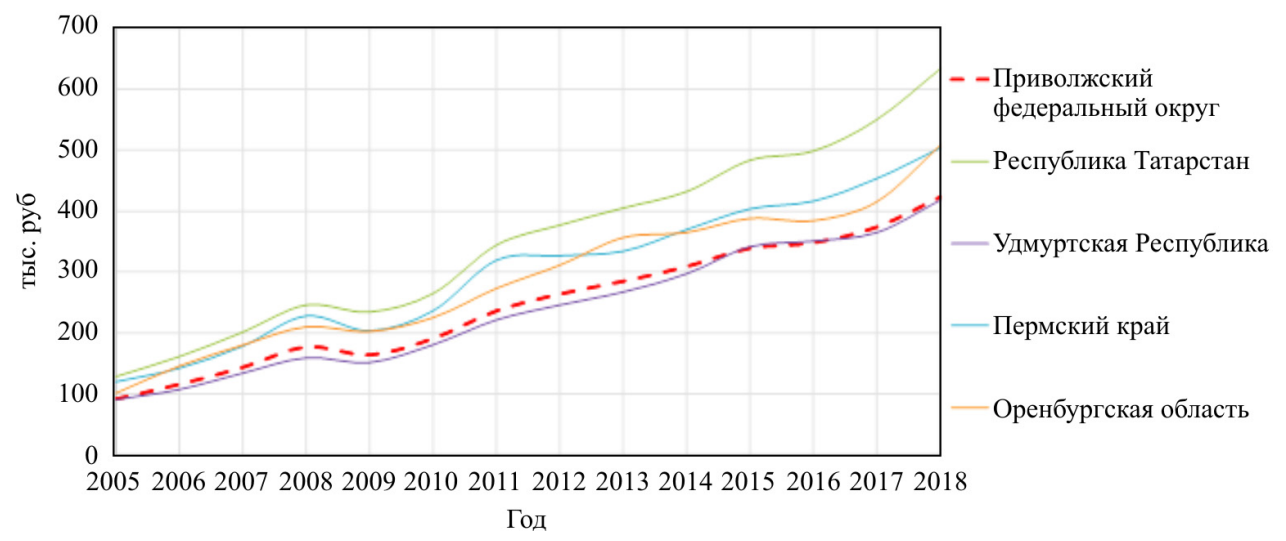

Рис. 1. ВРП на душу населения для группы 1 за период 2005-2018 гг. (абсолютные показатели)

Виден тренд снижения темпа роста валового регионального продукта после кризиса относительно докризисного периода. Однако регионы группы 2 более подвержены циклическому развитию, причем 
частота колебательных фаз насыщеннее и сильно зависит от конъюнктуры рынка (рис. 3, 4). Следовательно, регионы, ориентированные на обрабатывающую промышленность, имеют более высокую устойчивость экономики к внешним и внутренним факторам, чем регионы, для которых характерен вид экономической деятельности «добыча полезных ископаемых».

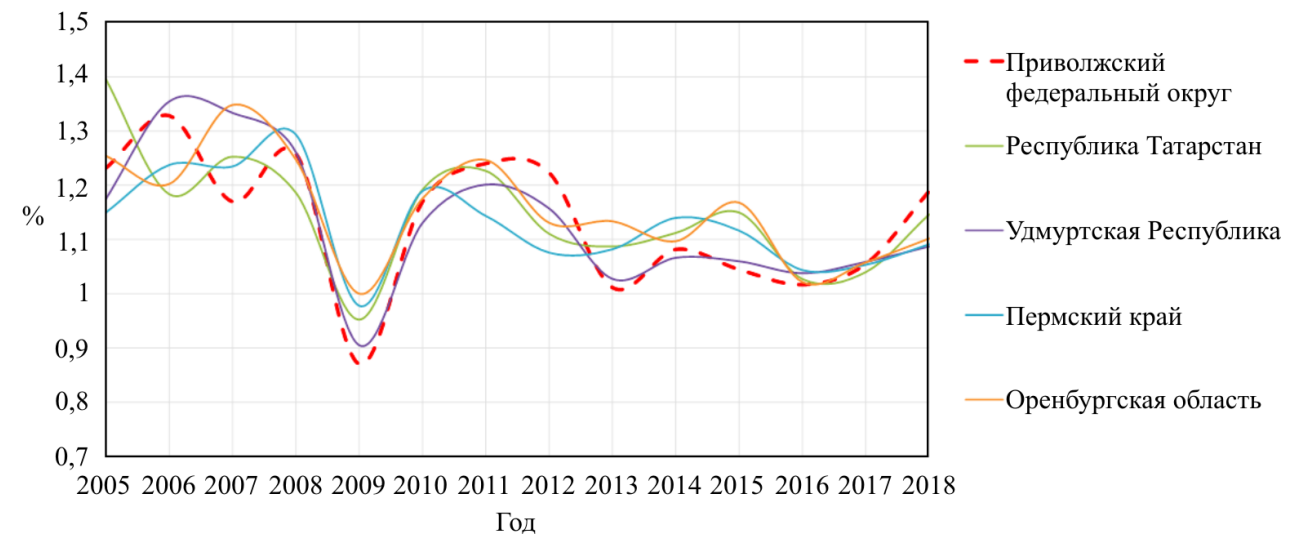

Рис. 2. ВРП на душу населения для группы 1 за период 2005-2018 гг. (относительные показатели)

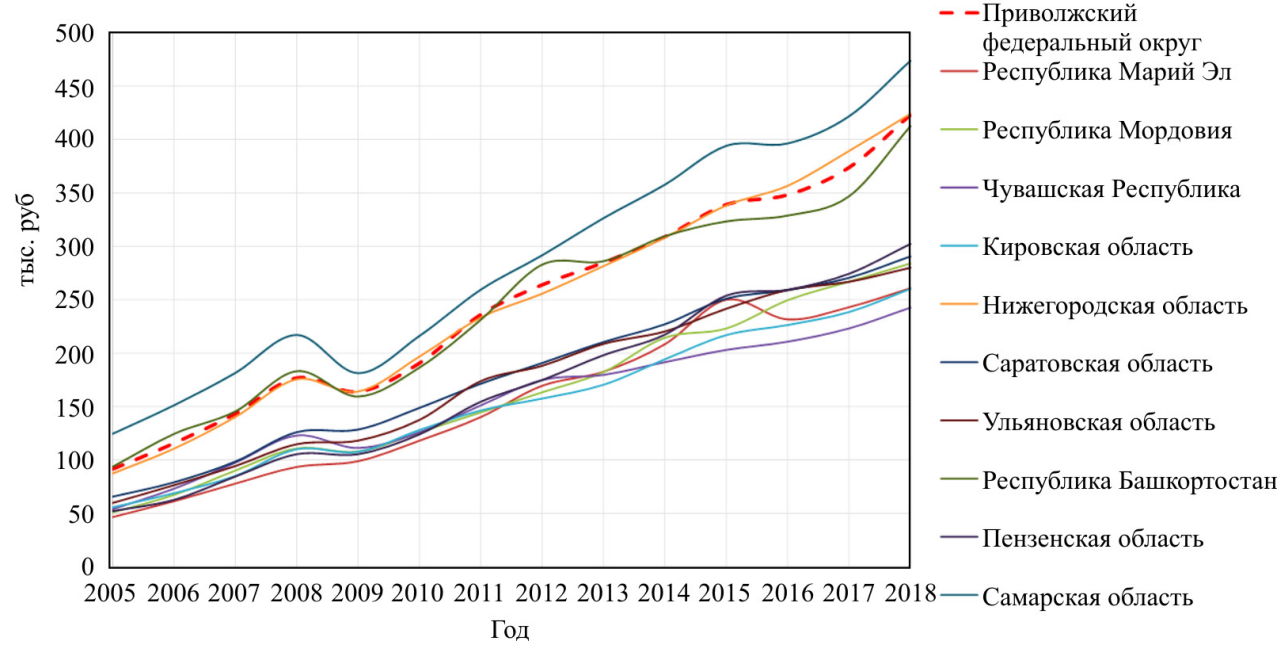

Рис. 3. ВРП на душу населения для группы 2 за период 2005-2018 гг. (абсолютные показатели) 


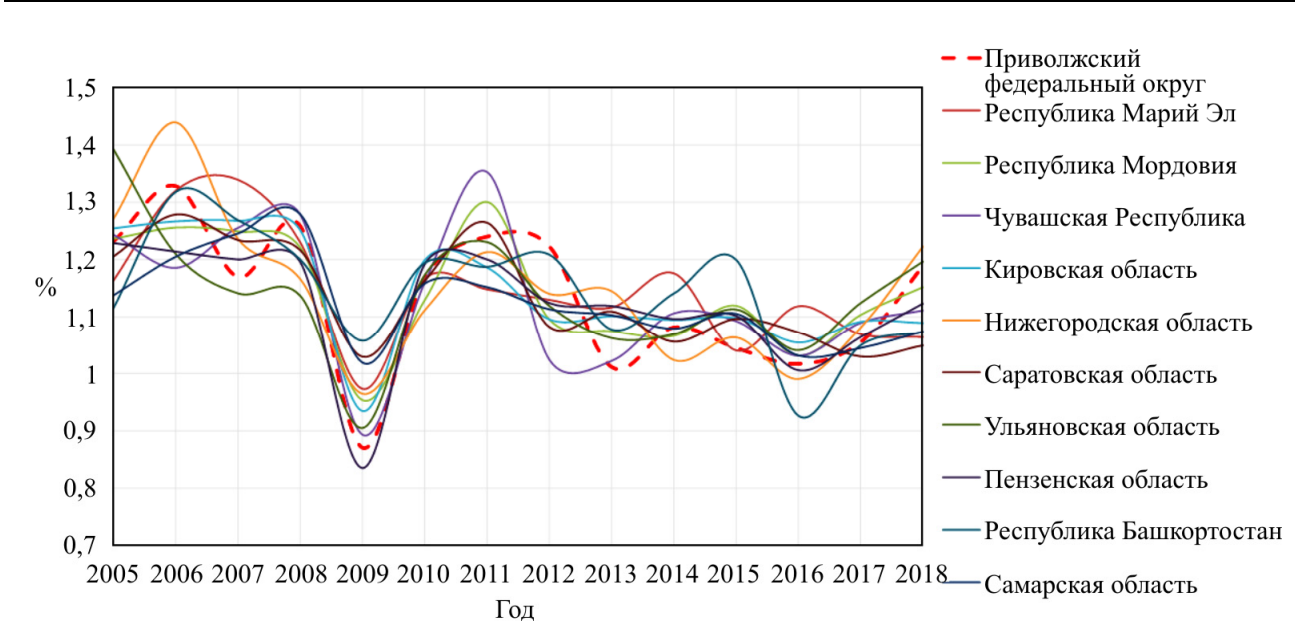

Рис. 4. ВРП на душу населения для группы 2 за период 2005-2018 гг.

(относительнье показатели)

Для определения преобладающего типа экономической деятельности и основных доминирующих подотраслей проведем анализ с использованием нейросетевого моделирования по всем регионам Российской Федерации. Исходя из результатов анализа Приволжского федерального округа, обучим нейронную сеть, где входными параметрами будут являться следующие:

$\mathrm{IEM}_{i j}$ - индекс производства по виду экономической деятельности «добыча полезных ископаемых»;

$\mathrm{IMA}_{i j}$ - индекс производства по виду экономической деятельности «обрабатывающие производства»;

$\mathrm{rGRP}_{i j}$ - темп валового регионального продукта на душу населения;

$k_{i}-$ индекс кластерной нагрузки.

Выходные значения будут заданы вектором-столбцом следующего вида: $\mu\{e, m\}$, где $e$ обозначает характерный тип отрасли для региона «добыча полезных ископаемых», $m$ - характерный тип отрасли «обрабатывающие производства».

Основываясь на трудах Л.Н. Ясницкого [5], где приведен подробный анализ основных подходов и методов нейросетевого моделирования, предложим оптимальный персептрон.

Долгое время не было возможности представить функцию многих переменных в виде суммы функций меньшего количества переменных. Получалось, что персептрон, сколько бы он нейронов не имел, не всегда 
мог построить аппроксимацию любой функции нескольких переменных. Сомнения относительно возможностей персептронов развеяли советские математики - академики А.Н. Колмогоров (1903-1987) и В.И. Арнольд (1937-2010). В своих работах они привели доказательство того, что любая непрерывная функция $n$ переменных $f\left(x_{1}, x_{2}, \ldots, x_{n}\right)$ всегда может быть представлена в композиционном виде непрерывных функций одной переменной или бинарной операцией сложения [6-9]:

$$
f\left(x_{1}, \ldots, x_{n}\right)=f_{1}\left(x_{1}\right)+f_{2}\left(x_{2}\right)+\ldots+f_{n}\left(x_{n}\right) .
$$

В 1987 г. профессором Калифорнийского университета (США) Р. Хехт-Нильсеном была опубликована статья [10], в которой теоремы Арнольда - Колмогорова были переработаны применительно к нейронным сетям. Была доказана принципиальная возможность построения нейронной сети, выполняющего преобразование при любом заданном множестве различных между собой обучающих примеров, причем универсальной нейронной сетью будет является двухслойный персептрон, т.е. персептрон с одним скрытым слоем, причем активационные функции его нейронов должны быть сигмоидными. Выбор активационной функции также находит свое подтверждение еще в одной универсальной теореме аппроксимации, доказанной Джорджем Цыбенко в 1989 г., в которой говорится, что искусственная нейронная сеть прямого распространения с одним скрытым слоем может аппроксимировать любую непрерывную функцию многих переменных с любой точностью, при условии, что сеть имеет в скрытом слое достаточное количество нейронов, имеющих сигмоидальную активационную функцию [11].

Таким образом, необходимое количество нейронов в скрытых слоях персептрона определим по формуле, являющейся следствием из теорем Арнольда - Колмогорова - Хехт-Нильсена:

$$
\frac{N_{y} Q}{1+\log _{2}(Q)} \leq N_{w} \leq N_{y}\left(\frac{Q}{N_{x}}+1\right)\left(N_{x}+N_{y}+1\right)+N_{y},
$$

где $N_{y}$ - размерность выходного сигнала; $Q$ - число элементов множества обучающих примеров; $N_{w}-$ необходимое число синаптических связей; $N_{x}$ - размерность входного сигнала.

Для построения нейронной сети воспользуемся базовым модулем Neural Net Time Series, представленным в программном продукте Matlab, в котором исходный код адаптирован применительно к нашей задаче. 
Согласно общепринятой технологии проектирования нейронных сетей все множество примеров разбивалось на обучающее Train, тестирующее Test и подтверждающеe Validation в соотношении 70 \%: $20 \%: 10 \%$.

В представленной работе множество примеров разобьем в соотношении: Train $-70 \%$, Test $-15 \%$, Validation - $15 \%$, что поможет скомпенсировать отсутствие большой базы статистических данных.

Исходя из формулы кластеризации и следствия теоремы Арнольда Колмогорова - Хехт-Нильсена (2), получен оптимальный интервал $4 \leq N \leq 60$ допустимого количества нейронов в скрытых слоях (рис. 5).

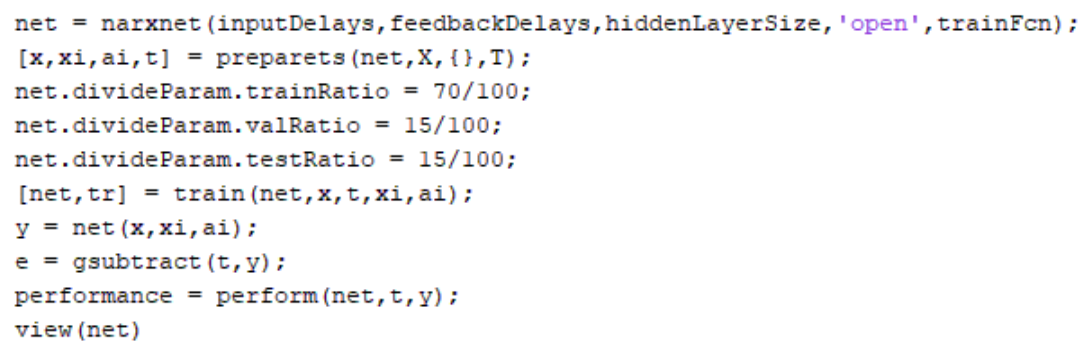

Рис. 5. Фрагмент кода выбора наиболее оптимального варианта метода обучения нейронной сети в Matlab

При обучении нейронной сети были использованы различные вариации наиболее распространенных методов: метод обратного распространения ошибки, метод упругого обратного распространения и метод Левенберга - Марквардта. Оптимизация структуры нейронной сети (выбор оптимального количества скрытых нейронов и активационных функций) проводилась вручную. Таким образом, мы имеем динамическую нелинейную авторегрессионную нейросеть с внешним входом для введения дополнительного параметра $x(t)$, влияющего на значение $y(t)$, причем рассмотрен вариант, когда данные о дополнительном параметре неизвестны и на внешний вход поступают предыдущие по времени значения исследуемого параметра $y(t)$ со следующими параметрами. Основные характеристики сети следующие:

- пять нейронов на скрытом слое;

- входной вектор задержки, скорректированный до параметра 1:4;

- вектор обратных задержек, скорректированный до параметра 1:4.

За функцию активации на первом слое принят гиперболический тангенс. На втором слое была использована линейная передаточная функция. Наилучший результат показала сетевая функция, которая об- 
новляет вес и значения смещения согласно обратной связи метода сопряженных градиентов. Также была рассмотрена сеть с замкнутым контуром для получения рекуррентной сети, но погрешность оказалась значительно больше, чем без замыкания контура, поэтому дальнейшая реализация такого типа сети не рассматривалась.

На рис. 6 представлена зависимость среднеквадратической ошибки от итерации обучения. Показаны оценки ошибки для трех наборов данных: тренировочного, валидационного и тестового. При этом обучение прекращается, когда ошибка на валидационном наборе данных перестает уменьшаться. В нашем случае нейронная сеть показала минимальную ошибку, закончив обучение на 37-й итерации (Epochs).

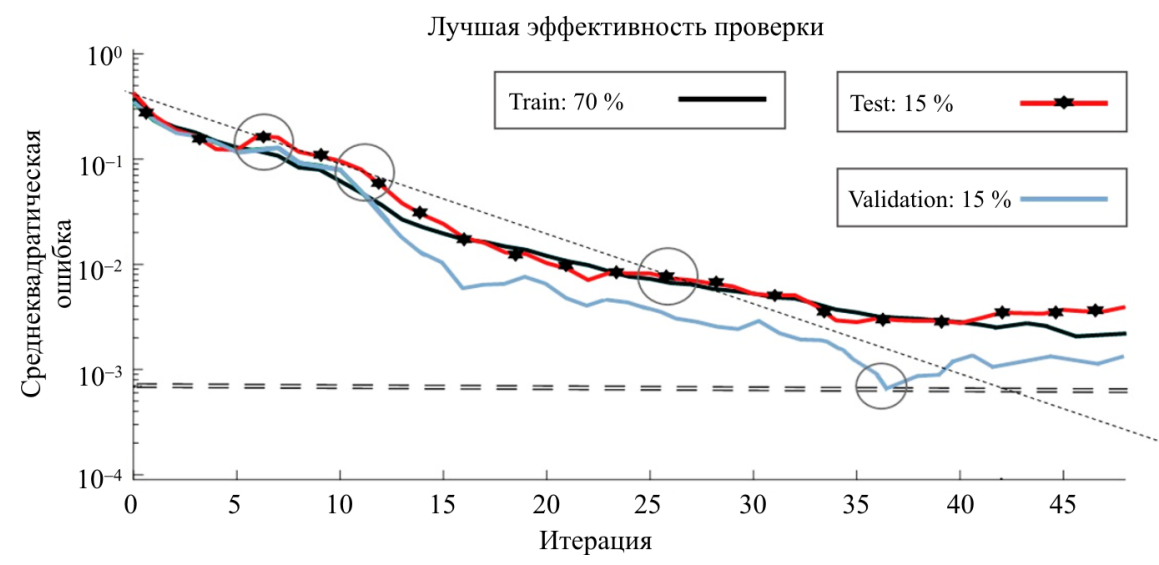

Рис. 6. Представление среднеквадратической ошибки от итерации обучения

Рассмотрим Пермский край подробнее. Для прогноза валового регионального продукта построим и обучим нейронную сеть на показателях Пермского края (рис. 7).

Средняя ошибка нейронной сети составила 1,15 \% (табл. 1). Таким образом, мы видим, что, продолжая увеличивать индекс кластерной нагрузки в Пермском крае, возможно добиться повышения показателя валового регионального продукта быстрее, чем без развития кластерно-сетевых связей.

Исходя из табл. 2 , составленной на основе ранжирования по консолидированной выручке за 2018 г., можно сказать, что Пермский край занимает высокие позиции по рейтингу при своем смешанном типе экономической деятельности, причем лидирующим направлением деятельности выступает нефтяная промышленность во главе с компаниями группы ПАО «Нефтяная компания „Лукойл“» [3]. 

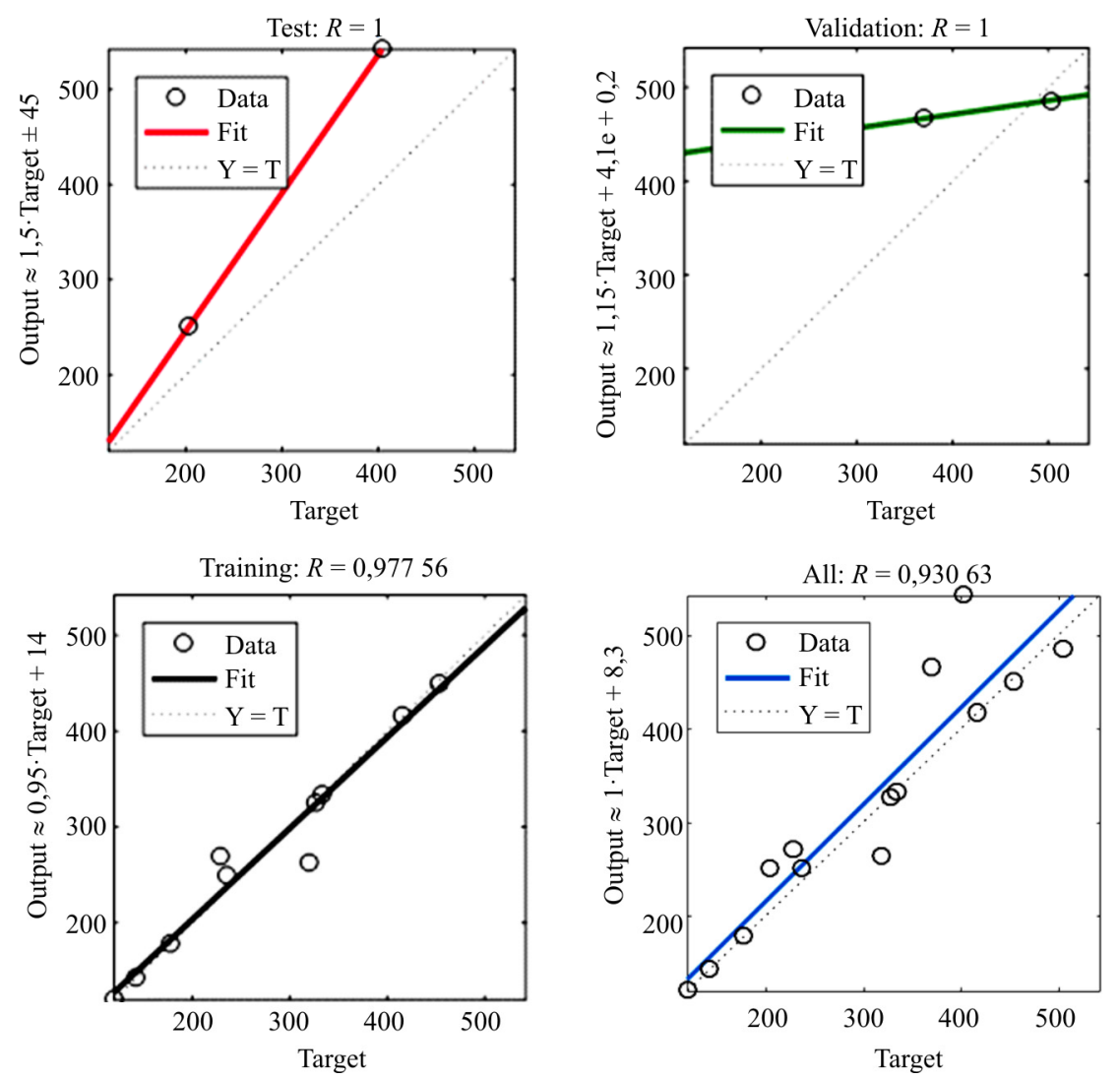

Рис. 7. Обобщающая способность нейронной сети

Таблица 1

Прогнозные показатели ВРП Пермского края

\begin{tabular}{|c|c|c|c|}
\hline$k$ & $\begin{array}{c}\text { Реальный показатель ВРП } \\
\text { на душу населения, } \\
\text { тыс. руб. }\end{array}$ & $\begin{array}{c}\text { Прогнозный показатель ВРП } \\
\text { на душу населения, тыс. руб., } \\
\text { с использованием нейронной сети }\end{array}$ & Отклонение, \% \\
\hline 0,6963 & 119,654 & 119,706 & 0,04 \\
\hline 0,7704 & 141,865 & 143,588 & 1,21 \\
\hline 0,7959 & 178,097 & 177,843 & 0,14 \\
\hline 0,9170 & 227,719 & 230,260 & 1,12 \\
\hline 0,8314 & 203,364 & 213,214 & 4,84 \\
\hline 0,8319 & 235,931 & 240,746 & 2,04 \\
\hline 0,8478 & 319,150 & 317,878 & 0,40 \\
\hline 0,9581 & 326,783 & 325,641 & 0,35 \\
\hline 1,3306 & 334,027 & 334,027 & 0,00 \\
\hline 1,4412 & 369,489 & 370,123 & 0,17 \\
\hline 1,4049 & 403,601 & 410,856 & 1,80 \\
\hline 1,4538 & 416,204 & 416,204 & 0,00 \\
\hline 0,8160 & 453,432 & 450,801 & 0,58 \\
\hline
\end{tabular}


Окончание табл. 1

\begin{tabular}{|c|c|c|c|}
\hline$k$ & $\begin{array}{c}\text { Реальный показатель ВРП } \\
\text { на душу населения, } \\
\text { тыс. руб. }\end{array}$ & $\begin{array}{c}\text { Прогнозный показатель ВРП } \\
\text { на душу населения, тыс. руб., } \\
\text { с использованием нейронной сети }\end{array}$ & Отклонение, \% \\
\hline 0,7628 & 503,818 & 486,507 & 3,44 \\
\hline 1,5000 & - & 421,575 & - \\
\hline 1,0000 & - & 431,987 & - \\
\hline 2,0000 & - & 529,898 & - \\
\hline 2,5000 & - & 579,456 & - \\
\hline
\end{tabular}

Таблица 2

Крупнейшие компании Приволжского федерального округа

\begin{tabular}{|c|l|l|l|c|}
\hline Место & \multicolumn{1}{|c|}{ Название компании } & \multicolumn{1}{|c|}{ Регион } & \multicolumn{1}{|c|}{$\begin{array}{l}\text { Основной вид } \\
\text { экономической } \\
\text { деятельности }\end{array}$} & $\begin{array}{c}\text { Выручка } \\
\text { в 2018 г., } \\
\text { млрд руб. }\end{array}$ \\
\hline 1 & $\begin{array}{l}\text { ПАО «Татнефть» им. } \\
\text { В.Д. Шашина }\end{array}$ & $\begin{array}{l}\text { Республика } \\
\text { Татарстан }\end{array}$ & Добыча сырой нефти & 910,5 \\
\hline 2 & $\begin{array}{l}\text { ПАО «Акционерная нефтяная } \\
\text { компания «Башнефть» }\end{array}$ & $\begin{array}{l}\text { Республика } \\
\text { Башкортостан }\end{array}$ & Добыча сырой нефти & 860,2 \\
\hline 3 & ГК «ТАИФ» & $\begin{array}{l}\text { Республика } \\
\text { Татарстан }\end{array}$ & $\begin{array}{l}\text { Производство нефте- } \\
\text { продуктов }\end{array}$ & 757,6 \\
\hline 4 & $\begin{array}{l}\text { ООО «ЛУКОЙЛ- } \\
\text { Нижегороднефтеоргсинтез» }\end{array}$ & $\begin{array}{l}\text { Нижегородская } \\
\text { область }\end{array}$ & $\begin{array}{l}\text { Производство нефте- } \\
\text { продуктов }\end{array}$ & 404,4 \\
\hline 5 & $\begin{array}{l}\text { ООО «ЛУКОЙЛ- } \\
\text { Пермнефтеоргсинтез» }\end{array}$ & Пермский край & $\begin{array}{l}\text { Производство нефте- } \\
\text { продуктов }\end{array}$ & 393,3 \\
\hline 6 & ООО «ЛУКОЙЛ-Пермь» & Пермский край & Добыча сырой нефти & 348,3 \\
\hline 7 & АО «Оренбургнефть» & $\begin{array}{l}\text { Оренбургская } \\
\text { область }\end{array}$ & Добыча сырой нефти & 313,9 \\
\hline 8 & АО «АвтоВАЗ» & $\begin{array}{l}\text { Самарская } \\
\text { область }\end{array}$ & $\begin{array}{l}\text { Производство легко- } \\
\text { вых автомобилей }\end{array}$ & 292,3 \\
\hline 9 & $\begin{array}{l}\text { ООО «Газпром нефтехим } \\
\text { Салават» }\end{array}$ & $\begin{array}{l}\text { Республика } \\
\text { Башкортостан }\end{array}$ & $\begin{array}{l}\text { Производство нефте- } \\
\text { продуктов }\end{array}$ & 261,2 \\
\hline 10 & АО «Самаранефтегаз» & $\begin{array}{l}\text { Самарская } \\
\text { область }\end{array}$ & Добыча сырой нефти & 255,3 \\
\hline
\end{tabular}

Пермский край - один из немногих в России и единственный в Приволжском федеральном округе регион, объединивший в себе всю нефтегазовую вертикаль: от геологоразведки до сбыта нефтепродуктов. Следовательно, структура ЛУКОЙЛ как вертикально-интегрированной компании имеет все формальные признаки кластера.

При прогнозировании влияния кластерной нагрузки с превалирующей нефтедобывающей отраслью в регионе для обучения нейронной сети будем использовать в качестве входных параметров чистую прибыль предприятия как один из ключевых показателей эффективности деятельности предприятия по специализирующейся деятельности - 
отрасли, валовой региональный продукт и соответствующий индекс кластерной нагрузки региона. Данные по федеральным округам, регионам взяты из ежегодных статистических сборников России [12]. Показатели годовой деятельности ПАО «ЛУКОЙЛ» и ООО «ЛУКОЙЛ-Пермь» взяты на официальном сайте предприятия в разделе «Бухгалтерская годовая отчетность предприятия».

Обученная нами сеть на ретроспективных данных дала максимальный процент ошибки прогноза: для ПАО «ЛУКОЙЛ» - 4 \%, ООО «ЛУКОЙЛ-Пермь» - 3 \% на тестовой выборке и позволяет нам в краткосрочной перспективе спрогнозировать прибыль предприятий при различных вариациях индекса кластерной нагрузки.

Под управлением кластерно-сетевыми связями на предприятиях промышленности (в данном случае предприятие сферы нефтегазового комплекса - группа предприятий ЛУКОЙЛ, ориентированных на доминирующую отрасль региона предприятия) будем понимать отклик прогнозных значений прибыли промышленного предприятия при изменении индекса кластерной нагрузки (рис. 8).

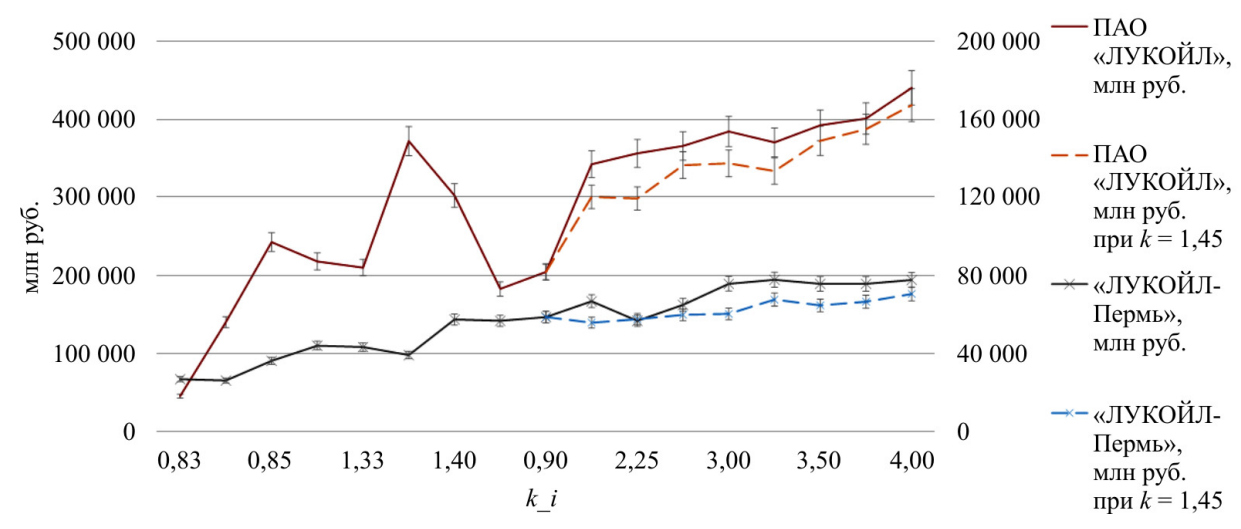

Рис. 8. Взаимосвязь $k$ и прибыли группы предприятий ЛУКОЙЛ

Результаты прогноза подтверждают гипотезу о благоприятности усиления-создания (концентрации) кластера с ведущей подотраслью «нефтедобывающее производство». В частности, можно сказать, что прибыль крупных предприятий, ориентированных на доминирующую отрасль, при увеличении индекса кластерной нагрузки будет увеличиваться намного интенсивнее, что характерно для кластерной экономики. 
В июне 2019 г. «Газпром нефть», правительство Тюменской области и Ассоциация нефтегазосервисных компаний приняли соглашение о создании регионального нефтепромышленного кластера. Причина данного соглашения - повышение социально-экономических показателей регионов, которые входят в этот проект. Согласно проекту, в кластер войдут 25 нефтесервисных и промышленных предприятий, ряд банков, технопарки и вузы [13]. В свою очередь, цель компании «Газпром нефть» - занять лидирующие позиции в своей отрасли по технологичности. Это еще раз подтверждает актуальность и востребованность развития кластерной политики.

Если рассматривать анализ процессов в нефтегазовой отрасли, то наиболее высокая эффективность производства в нефтяной сфере РФ достигается за счет управления промышленными компаниями в форме «АО вертикально-интегрированная нефтяная компания» [14]. Интегрирование отдельных производств способствует увеличению их продолжительности жизнеспособности из-за «перелива» капитала. Более того, повышается эффективность осведомленности государства об интересах производителя.

Таблица 3

\section{Сравнительная таблица вертикально-интегрированной}

структуры и кластерного подхода [15]

\begin{tabular}{|c|c|c|}
\hline $\begin{array}{l}\text { Критерий } \\
\text { сравнения }\end{array}$ & $\begin{array}{c}\text { Вертикально- } \\
\text { интегрированные структуры }\end{array}$ & $\begin{array}{l}\text { Кластерный } \\
\text { подход }\end{array}$ \\
\hline \multicolumn{3}{|c|}{ Производственные процессы } \\
\hline Характер производства & $\begin{array}{l}\text { Жесткий контроль всей про- } \\
\text { изводственной цепочки со } \\
\text { стороны компании }\end{array}$ & $\begin{array}{l}\text { Инновационный подход. Гибкая специа- } \\
\text { лизация - интеграция деятельности всех } \\
\text { взаимосвязанных групп и отсутствие } \\
\text { между ними формальной «перегородки» }\end{array}$ \\
\hline Структура производства & $\begin{array}{l}\text { Строгая централизация про- } \\
\text { изводственной цепочки }\end{array}$ & $\begin{array}{l}\text { Координация и согласование между } \\
\text { независимыми предприятиями }\end{array}$ \\
\hline \multicolumn{3}{|c|}{ Организационно-управленческая структура } \\
\hline Состав предприятий & $\begin{array}{l}\text { Жестко закреплен. Вход и } \\
\text { выход возможны только после } \\
\text { передачи прав собственности }\end{array}$ & $\begin{array}{l}\text { Вариативность различных форм собст- } \\
\text { венности и отраслевой принадлежности. } \\
\text { Свободное изменение состава кластера }\end{array}$ \\
\hline Оценка эффективности & $\begin{array}{l}\text { По социально-экономическим } \\
\text { показателям отрасли }\end{array}$ & $\begin{array}{l}\text { По показателям эффективности разви- } \\
\text { тия регионов }\end{array}$ \\
\hline \multicolumn{3}{|c|}{ Внешнее окружение } \\
\hline \multirow[t]{2}{*}{ Характер конкуренции } & $\begin{array}{l}\text { Отсутствие конкуренции } \\
\text { внутри структуры. Малые и }\end{array}$ & $\begin{array}{l}\text { Ограниченное присутствие конкурен- } \\
\text { ции внутри структуры }\end{array}$ \\
\hline & $\begin{array}{l}\text { средние компании не выдер- } \\
\text { живают конкуренции }\end{array}$ & $\begin{array}{l}\text { Появляется возможность развития ма- } \\
\text { лых и средних компаний }\end{array}$ \\
\hline Ценовая политика & $\begin{array}{l}\text { Ценовой диктат реализации } \\
\text { продукта за счет монопольно- } \\
\text { го положения }\end{array}$ & $\begin{array}{l}\text { Сглаживание резких перепадов цен за } \\
\text { счет внутренней и внешней конкуренции }\end{array}$ \\
\hline
\end{tabular}


Сравнивая основные показатели, характерные для вертикальноинтегрированных компаний и кластера (табл. 3), можно предположить, что оптимальным управлением региона, ориентированного на обрабатывающую и добывающую отрасли, будет развитие на существующей структуре ВИНК «ЛУКОЙЛ» топливно-энергетического кластера, где ядром кластера может являться ВИНК «ЛУКОЙЛ». Это может поспособствовать наращиванию стратегических инициатив и росту прибыли компании нефтегазового комплекса, что скажется на укреплении и улучшении социально-экономических показателей путем притока новой рабочей силы и инвестирования различных проектов, тем самым повысится эффективность функционирования как региона, так и самого предприятия [15].

Для создания эффективного механизма управления кластерносетевыми связями государству необходимо выработать адекватную политику, которая подразумевает связь всех уровней государственных органов власти и предприятий, обеспечивающих нефтегазодобывающую отрасль, а также создать эффективную и оптимальную инфраструктуру поддержки кластерных образований и институтов управлениями ими.

\section{Список литературы}

1. Первадчук В.П., Осипова М.Ю., Кожемякин Л.В. Эконометрическое моделирование кластерно-сетевых взаимодействий // Экономика и предпринимательство. - 2019. - № 10 (111) - С. 978-983.

2. Кожемякин Л.В., Пушкарев Г.А., Толстоброва Н.А. Анализ нефтедобывающего сектора в условиях вынужденной локализации экономики Российской Федерации // Экономика и управление: проблемы, решения. - 2019. Т. 11, № 3 (87). - С. 132-139.

3. Кожемякин Л.В. Определение критической массы ядра нефтедобывающего кластера с использованием теории графов [Электронный ресурс] // Моделирование, оптимизация и информационные технологии. -2020 . - № 8(3). 10 c. - URL: https://moit.vivt.ru/wp-content/uploads/2020/08/Kozhemyakin_3_20_1.pdf. DOI: 10.26102/2310-6018/2020.30.3.015 (дата обращения 11.02.2020).

4. Михалев Д.А. Моделирование процессов формирования и развития региональных промышленных кластеров: дис. ... канд. экон. наук. - Иваново, 2015. -223 c.

5. Ясницкий Л.Н. Искусственный интеллект. Элективный курс: учеб. пособие. - М.: БИНОМ. Лаборатория знаний. 2011. - 197 с.

6. Колмогоров А.Н. О представлении непрерывных функций нескольких переменных суперпозициями непрерывных функций меньшего числа переменных // Доклады АН СССР. - 1956. - Т. 108, № 2. - С. 179-182. 
7. Колмогоров А.Н. О представлении непрерывных функций нескольких переменных в виде суперпозиции непрерывных функций одного переменного и сложения // Доклады АН СССР. - 1957. - Т. 114, № 5. - С. 953-956

8. Арнольд В.И. О функции трех переменных // Доклады АН СССР. 1957. - Т. 114, № 4. - С. 679-681.

9. Арнольд В.И. О представлении непрерывных функций трех переменных суперпозициями непрерывных функций двух переменных // Математический сборник. - 1959. - Т. 48(90), № 1. - С. 3-74.

10. Hecht-Nielsen R. Kolmogorov's mapping neural network existence theorem // IEEE First Annual Int. Conf. on Neural Networks, San Diego. - San Diego, 1987. - Vol. 3. - P. 11-13.

11. Cybenko G. Approximiation by superpositions of sigmoidal functions // Mathematics of Control Signals and Systems. - 1989. - Vol. 2, no. 4. - P. 303-314.

12. Регионы России. Социально-экономические показатели [Электронный ресурс] / Фед. служба гос. стат. - 2018 - URL: http:/www.gks.ru/ bgd/regl/b18 14p/Main.htm. (дата обращения: 07.12.2019).

13. Профессионально о нефти [Электронный ресурс] // Рrонефть. 2019. - № 4. - 6 c. - URL: https://ntc.gazprom-neft.ru/upload/uf/f60/GPN4_2019150-dpi.pdf (дата обращения: 11.02.2020).

14. Алекперов В.Ю. Вертикально-интегрированные нефтяные компании России. - М.: АУТОПАН, 1996. - 217 с.

15. Кожемякин Л.В. Об управлении кластерно-сетевым взаимодействием объектов нефтегазового комплекса с использованием нейросетевого моделирования // Вопросы технических наук: новые подходы в решении актуальных проблем: сб. науч. тр. по итогам междунар. науч.-практ. конф., г. Казань, 11 июня 2020 г. / ИЦРОН. - Н. Новгород, 2020. - Вып. 7. - С. 9-12.

\section{References}

1. Pervadchuk V.P., Osipova M.Yu., Kozhemyakin L.V. Ekonometricheskoe modelirovanie klasterno-setevykh vzaimodeistvii [Econometric Modeling of Cluster-Network Interactions]. Economics and Entrepreneurship, 2019. no. 10 (111), pp. 978-983.

2. Kozhemyakin L.V., Pushkarev G.A., Tolstobrova N.A. Analiz neftedobyvaiushchego sektora $\mathrm{v}$ usloviiakh vynuzhdennoi lokalizatsii ekonomiki Rossiiskoi Federatsii [Analysis of the oil-producing sector in the conditions of forced localization of the Russian Federation economy]. Economics and management: problems and solutions. 2019. vol. 11. no. 3 (87), pp. 132-139.

3. Kozhemyakin L.V. Opredelenie kriticheskoi massy iadra neftedobyvaiushchego klastera $\mathrm{s}$ ispol'zovaniem teorii grafov. Modelirovanie, optimizatsiia i informatsionnye tekhnologii [Determination of the critical mass of 
the core of an oil-producing cluster using graph theory]. Modeling, optimization, and information technology, 2020, no. 8(3), 10 p., available at: https://moit.vivt.ru/wp-content/uploads/2020/08/Kozhemyakin_3_20_1.pdf DOI: 10.26102/2310-6018/2020.30.3.015

4. Mikhalev D.A. Modelirovanie protsessov formirovaniia i razvitiia regional'nykh promyshlennykh klasterov[Modeling of processes of formation and development of regional industrial clusters] Ph. D Thesis. 2015. $223 \mathrm{p}$.

5. Yasnitsky L.N. Iskusstvennyi intellekt. Elektivnyi kurs [Artificial intelligence. Elective course]. Moscow, BINOM. Laboratory of knowledge. 2011. 197 p.

6. Kolmogorov A.N. Predstavlenii nepreryvnykh funktsii neskol'kikh peremennykh superpozitsiiami nepreryvnykh funktsii men'shego chisla peremennykh. [On the representation of continuous functions of several variables as superposition of continuous functions of one variable and addition] Doklady Mathematics, 1956. vol. 108, no. 2. pp. 179-182.

7. Kolmogorov A.N. Predstavlenii nepreryvnykh funktsii neskol'kikh peremennykh superpozitsiiami nepreryvnykh $\mathrm{v}$ vide superpozitsii nepreryvnykh funktsii odnogo peremennogo i slozheniia. [On the representation of continuous functions of several variables in the form of a superposition of continuous functions of one variable and addition] Doklady Mathematics, 1957. vol. 114, no. 5. pp. 953-956.

8. Arnold V.I. O funktsii trekh peremennykh [On the function of three variables] Doklady Mathematics, 1957. vol. 114, no. 4. pp. 679-681.

9. Arnold V.I. O predstavlenii nepreryvnykh funktsii trekh peremennykh superpozitsiiami nepreryvnykh funktsii dvukh peremennykh [On the presentation of continuous functions of three variables by superpositions of continuous functions of two variables]. Sbornik: Mathematics. 1959. vol. 48 (90). no. 1, pp. 3-74.

10. Hecht-Nielsen R. Kolmogorov's. Mapping neural network existence theorem. IEEE First Annual Int. Conf. on Neural Networks, San Diego, 1987. vol. 3. pp. 11-13.

11. Cybenko G. Approximiation by superpositions of sigmoidal functions. Mathematics of Control Signals and Systems. 1989. vol. 2, no. 4, pp. 303-314

12. The Regions of Russia. Socio-economic indicators-2018 Official website of the Federal state statistics service. [Electronic resource]. - URL: http://www.gks.ru/bgd/regl/b18_14p/Main.htm. (accessed: 07.12.2019)

13. Rgoneft. Professionally about oil. 2019. no. 4. pp. 6. URL: https://ntc.gazprom-neft.ru/upload/uf/f60/GPN4_2019-150-dpi.pdf (accessed: 11.02.2020)

14. Alekperov V.Yu. Vertikal'no integrirovannye neftianye kompanii Rossii [Vertically integrated oil companies of Russia]. Moscow: AUTOPAN, 1996, 217 p.

15. Kozhemyakin L.V. Ob upravlenii klasterno-setevym vzaimodeistviem ob"ektov neftegazovogo kompleksa s ispol'zovaniem neirosetevogo modelirovaniia 
[On Managing Cluster-Network Interaction of Oil and Gas Complex Facilities Using Neural Network Modeling. In Questions of Technical Sciences: New Approaches to Solving Actual Problems. Collection of Scientific Papers on the Results of the International Scientific and Practical Conference, No. 7, Kazan. Nizhny Novgorod: ICRON. pp. 9-12.

Статья получена: 16.10 .2020

Статья принята: 16.11 .2020

\section{Сведения об авторе}

Кожемякин Леонид Валерьевич (Пермь, Россия) - аспирант кафедры «Прикладная математика», Пермский национальный исследовательский политехнический университет (614990, Пермь, Комсомольский пр., 29, e-mail: lvkozhemyakin@yandex.ru).

\section{About the author}

Leonid V. Kozhemyakin (Perm, Russian Federation) - Ph.D. Student, Department of Applied Mathematics, Perm National Research Polytechnic University (29, Komsomolsky av., Perm, 614990, e-mail: lvkozhemyakin@yandex.ru).

\section{Библиографическое описание статьи согласно ГОСТ Р 7.0.100-2018:}

Кожемякин, Л.В. Применение нейронных сетей в моделировании кластерносетевых связей в нефтегазовой отрасли / Л.В. Кожемякин. - DOI 10.15593/24999873/2020.4.09. - Текст: непосредственный // Прикладная математика и вопросы управления = Applied Mathematics and Control Sciences. -2020 . - № 4. - C. 137-152.

\section{Цитирование статьи в изданиях РИНЦ:}

Кожемякин Л.В. Применение нейронных сетей в моделировании кластерносетевых связей в нефтегазовой отрасли // Прикладная математика и вопросы управления. - 2020. - № 4. - С. 137-152. DOI: 10.15593/2499-9873/2020.4.09

\section{Цитирование статьи в references и международных изданиях:}

Cite this article as:

Kozhemyakin L.V. Application of neural networks in simulation of cluster-network relations in oil and gas industry. Applied Mathematics and Control Sciences, 2020, no. 4, pp. 137-152. DOI: 10.15593/2499-9873/2020.4.09 (in Russian) 